\title{
$\begin{array}{llllllll}R & \text { E } & S & \text { E } & N & H & \text { A } & S\end{array}$
}

é objeto de investigação detalhada e inédita. São discutidas também as turbulências sociais que afetaram a capitania no século XVII.

O livro se encerra com a quarta parte, que direciona a investigação para ainda outra dimensão de análise e trata agora da escala local, isto é, da "Cidade de São Sebastião”, do pequeno núcleo urbano com estatuto de cidade que permaneceu como burgo secundário no contexto colonial até que a riqueza das minas viesse a transformar bastante a sua forma e o seu conteúdo no século XVIII. Discutem-se aqui as diversas morfologias da cidade, tanto no Quinhentos como no Seiscentos, como também a sua organização interna, os seus conflitos e controles, assim como o importante papel exercido na urbe por mercadores, oficiais mecânicos e escravos urbanos; destaca-se, igualmente, o seu quotidiano pacato, mas que era sacudido, de tempos em tempos, por atividades festivas que transfiguravam o espaço coletivo e, sobretudo, pelo frenesi da chegada e permanência das frotas do açúcar, época em que a cidade se transformava inteiramente.” (p. 27-8)

Deve ser destacada também a parte gráfica do livro, a qualidade das imagens pesquisadas, assim como a importância da cartografia histórica em que o autor procurou localizar fenômenos, como no caso das sesmarias, das terras da Câmara e das ordens religiosas, que por si só já seria suficiente para qualificar o trabalho. Outro destaque a ser dado foi o trabalho inédito de levantamento e localização da quase totalidade dos engenhos de açúcar fluminenses, um verdadeiro quebra-cabeça que ele conseguiu juntar e recuperar, um feito que os historiadores não tinham conseguido.

Além do mais, o livro também traz uma dimensão teórica, com a citação de uma rica bibliografia internacional, mantendo sempre uma coerência interna de não se afastar da sua preocupação principal de "trabalhar a relação entre processo social e forma espacial num lugar do passado" (p.27), o que pode ser confirmado pelo exame dos seus pares dialéticos: "relacionar o conhecimento histórico com o geográfico, a narração com a descrição, a grande escala com a pequena, a sincronia com a diacronia, a indução com a dedução, a análise com a síntese, o processo social com a forma social" (p.462), ou seja, preocupações que identificam o seu trabalho como sendo de Geografia Histórica, o que o diferencia, portanto, dos estudos históricos tradicionais. Sua qualidade principal, entretanto, é a de recuperar parte importante do passado da cidade de São Sebastiāo do Rio de Janeiro nos seus dois séculos iniciais, uma contribuição com dimensões braudelianas e que vem consolidar a Geografia Histórica brasileira.

\section{UMA ESTRATÉGIA CHAMADA "PLANEJAMENTO ESTRATÉ- GICO". DESLOCAMENTOS ESPACIAIS E ATRIBUIÇÃO DE SENTIDOS NA TEORIA DO PLANEJAMENTO URBANO}

Pedro Novais

Rio de Janeiro: 7 Letras, 2010

\author{
Ana Fernandes \\ Professora Associada da FAU-UFBA, \\ pesquisadora do $\mathrm{CNPq}$
}

Em seus cinco capítulos, este livro, leitura obrigatória para a área, nos conduz através das tramas que nos fizeram conhecer, ao longo dos anos 1990, a disseminação da estratégia chamada planejamento estratégico como modo de conceber, operar e agir sobre as cidades. Resultado de sua tese de doutorado, defendida no IPPUR-UFRJ em 2003, Pedro Novais recompõe, de forma clara e concisa, a emergência, o percurso e a difusão desse conceito, seguindo, com precisão quase cirúrgica, seus condicionantes e desdobramentos teóricos e empíricos, bem como suas aderências temporais e territoriais. Harvard, Barcelona, Rio de Janeiro são os espaços privilegiados para a análise proposta, por corresponderem a características e momentos específicos do planejamento estratégico para as cidades: grosso modo e respectivamente, à sua invenção (anos 1970-80), à sua modelização (anos 1980-90) e à sua experimentação pela primeira vez no Brasil (anos 1990).

Logo de início, no primeiro capítulo, "A emergência das políticas competitivas", após um sucinto panorama das políticas urbanas recentes e dos modelos de planejamento, nos são apresentados os instrumentos conceituais através dos quais se propõe a construção do objeto e sua decorrente leitura. Partindo da crítica a uma visão de cunho intelectualista da produção de ideias no planejamento urbano - no qual elas são 
tratadas circularmente, em uma esfera de quase autonomia -, o autor elege os conceitos de habitus, espaço social e campo, tal como formulados por Bourdieu, para possibilitar a compreensão das condições sociais do seu desenvolvimento, bem como da disputa permanente em torno da sua significação e legitimidade. A construção teórico-metodológica elaborada mostra-se extremamente profícua para os estudos que tratam da produção e circulação de ideias. Tensionando de forma continuada a relação entre conceitos (e sua coerência), agentes, práticas e interesses, e entendendo, também como Bourdieu, que o "real é relacional", a densa construção do planejamento estratégico de cidades vai se fazendo conhecer através de uma pesquisa e de uma análise rigorosamente estabelecidas.

Espaço intelectual entendido "como uma interseção: entre saberes disciplinares, entre domínios estatais e entre acadêmicos e profissionais" (p.48), o urbanismo e o planejamento urbano, em sua versão estratégica, serão enfocados em sucessivas ondas analíticas, desde o contexto mais geral, até o perfil e o papel de alguns de seus principais protagonistas, entendidos como emanação do espaço social. São assim apreendidos, para cada caso, a contextualização social e política, a produção intelectual da área, as experiências singulares da prática, as redes de relaçôes, inclusive os contatos interoceânicos, a caracterização dos agentes envolvidos, o trabalho político da construção das ideias e a realidade institucional, o trabalho intelectual de codificação e as disputas intracampo. O resultado é instigante.

"Harvard e a invenção do planejamento estratégico de cidades" é o tema do segundo capítulo, um avanço importante em termos da discussão sobre o espraiamento da lógica da ação empresarial estratégica para a ação pública nas cidades. Aqui está demonstrada, de forma exemplar, a operação intelectual (e política) que desloca o sentido do planejamento. Em primeiro lugar, ela identifica o setor público com o setor privado, em função da semelhança entre a situação e os desafios colocados pela incerta e instável nova conjuntura mundial. A partir desse determinismo do contexto, movimentos de construção de argumentos serão feitos visando estabelecer que o método estratégico e o setor público podem e devem ser confluentes no processo de problematização da realidade e consequente ação sobre ela. As equivalências então construídas entre público e privado serão transferidas, de forma já bastante natura- lizada, para as relações entre empresa e cidade - a cidade é tornada sujeito da ação - e entre visão estratégica e planejamento urbano.

Merece ainda destaque, nesse capítulo, a análise das disputas internas ao campo do planejamento urbano, no qual o autor continua a tensionar a esfera da produção intelectual, analisando com muita perspicácia o lugar de onde falam os produtores de teorias e narrativas. A caracterização desses personagens em termos de poder acadêmico, entendido como a ocupação de cargos e representações, e de poder científico, definido como a capacidade de elaboração de teorias, permite uma interessante percepção das posições de adesão e de crítica relativas ao planejamento estratégico de cidades.

A realização do Plano Estratégico de São Francisco (1983), considerado pioneiro, e a ação de corporações internacionalizadas de consultoria constroem os elos necessários ao terceiro capítulo e à experiência catalã.

"Barcelona: identidade, oportunidade e consenso" trata da modelização do planejamento estratégico de cidades e da construção de uma plataforma para sua "exportação". A recepção da experiência estadounidense, demonstrada pela circulação biográfica ou bibliográfica de seus principais protagonistas em território espanhol, foi devidamente contextualizada por um conjunto de injunções: embate das tradições políticas e culturais autonomistas da região, crise econômica generalizada do país, transformaçōes estruturais de perspectivas, com a construção mais efetiva da União Europeia e com a ressignificação dos eventos esportivos como aglutinadores de redes midiáticas e produtivas. Talvez pudesse ser aqui agregado também o processo de relançamento da Espanha como ex-potência colonial, agora democratizada, explicitada através de forte ação diplomática junto aos países latino-americanos, seja através da criação, em 1991, das Cumbres Iberoamericanas de Jefes de Estado y de Gobierno, seja aglutinada em torno da comemoração dos 500 anos da chegada de Colombo às Américas.

O complexo processo descrito pelo autor alia a particularização do planejamento estratégico na experiência catalã com a sua transformação em modelo, ou seja, na construção de "correspondência entre uma situação determinada, tomada como problema, e uma resposta a essa situação" (p.135). Temos então a possibilidade de acompanhar, com riqueza de nuances e inflexões, essa construção intelectual que "visava 
dar sentido às decisōes, dar legitimidade às práticas e [que], por fim, tornou-se um modelo a ser difundido" (p.129). A mobilização social, cultural e política em torno da cidade - entendida como fórum de interesse comum e como espaço de desenvolvimento econômico - traduzir-se-á em participação através do consenso como técnica de governo. A constituição do CIDEU - Centro Iberoamericano de Desarrollo Estratégico Urbano - em 1993 expressa de forma lapidar a possibilidade aberta de fazer circular, através de consultoria especializada, este novo produto da cesta de serviços: o plano estratégico de cidades. É curioso constatar que, no documento final da III Cumbre Iberoamericana de Jefes de Estado y de Gobierno, realizada em Salvador (BA) em julho de 1993, o tópico n.38 versa sobre as grandes cidades. Afirma-se que

Hemos sido informados de las conclusiones de la I Conferencia de Ciudades para el Siglo XXI, realizada en Río de Janeiro los días 3 al 5 de junio de 1993 (anexo n.8), donde fueron examinados los problemas urbano-ambientales que afectan particularmente a las grandes ciudades latinoamericanas. Se enfatizó, en dicha ocasión, la importancia del intercambio amplio y sistemático de experiencias en esa área y la necesidad de que las agencias internacionales de desarrollo y reconstrucción otorguen atención a los esfuerzos e iniciativas que realizan por las comunidades locales iberoamericanas. La Conferencia de Ciudades apoyó la iniciativa de crear el Centro Iberoamericano de Desarrollo Estratégico Urbano (CIDEU), en Barcelona. ${ }^{1}$

É nessa perspectiva que trabalha o quarto capítulo, "Rio de Janeiro: elites políticas e disputas intelectuais", no qual novamente atravessamos o Atlântico, mas agora também o Equador. A experiência da elaboração do Plano Estratégico da Cidade do Rio de Janeiro (1993-1995), que inaugura no país essa forma de ação pública sobre as cidades, será abordada com riqueza analítica e ineditismo de informaçōes, dessa vez contando também com diversas entrevistas realizadas com seus principais protagonistas. Contexto, interpretações, articulações, tensionamentos, transformações, decisões e encaminhamentos: o

1 Disponível em <http://www.oei.es/iiicumbr.htm>. Acesso em 07/02/2011. processo de construção do PECRJ ganha nitidez; e é interessante observar como a formulação teórica e propositiva do planejamento estratégico para a cidade deriva da própria compreensão de estratégia adotada por cada dirigente envolvido, e oscila entre escalas e domínios conceituais, indo do alinhamento a um projeto nacional, a uma técnica de governo, ou ainda, a um desenvolvimento urbano com fortes acentos paroquiais. A problematização do espaço e do território também comparece, como ênfase ou como lacuna, a depender das adesões disciplinares de cada produtor intelectual, eles próprios devidamente enquadrados e caracterizados em seu quinhão de capital simbólico.

Nas conclusões do trabalho, "Planejamento Estratégico como Estratégia”, retoma-se teoricamente o percurso analisado, em que cada decisão metodológica dá lugar a uma perspectiva analítica prenhe de possibilidades. Ao eleger estudar a gênese e difusão de um modelo de planejamento a partir de seu espaço social de produção e circulaçãa, diferenciando contextos, agentes, conjunções, interesses e posições, Pedro Novais amplia as possibilidades de abordagem das longas viagens de ideias e de práticas, ultrapassando o simplismo do pensamento endogenista e incorporando-as aos complexos processos intelectuais a que todos estamos submetidos.

\section{PLANO GERAL DE MELHORA- MENTOS DE PORTO ALEGRE: O PLANO QUE ORIENTOU A MODERNIZAÇÃO DA CIDADE}

Célia Ferraz de Souza

Porto Alegre: Armazém Digital, 2010

Rodrigo Santos de Faria

Professor Adjunto da FAU-UnB

Naquele que considero um dos números mais importantes da Revista Espaço \& Debates, o 34, cujo tema é "Cidade e História", um conjunto de pequenos (mas de extrema importância) depoimentos aborda, cada qual em suas especificidades, questões fundamentais para os pesquisadores arquitetos e urbanistas dedicados aos estudos historiográficos. O primeiro deles, denominado "O estatuto da História", de autoria do 